\title{
Autodescrição de Adolescentes segundo o Gênero e a Ordem de Nascimento ${ }^{1}$
}

Adolescents' Self-Descriptions According to Gender and Birth Order

Auto descripción de Adolescentes según el Género y el Orden de Nacimiento

Izabela Tissot

Antunes Sampaio \& Mauro Luís Vieira

Universidade

Federal de Santa

Catarina

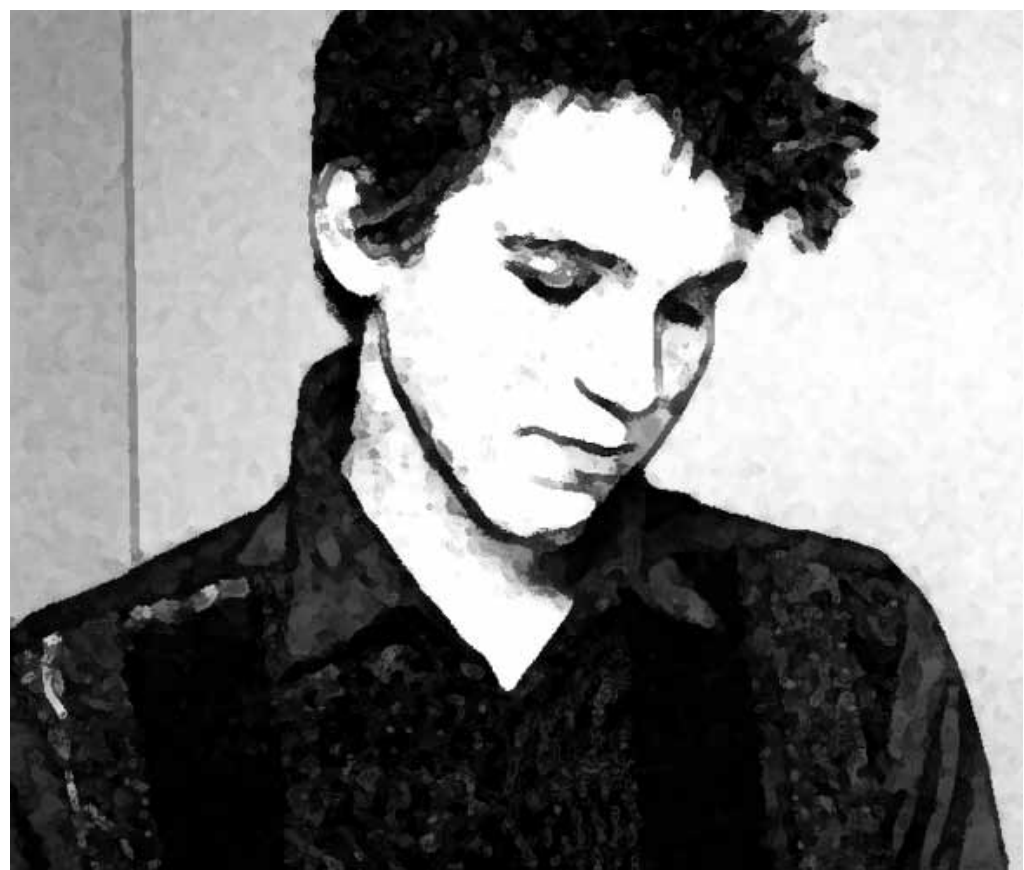


Resumo: Este artigo tem como objetivo divulgar resultados e suscitar o interesse de pesquisadores sobre a influência do gênero e de ordem de nascimento na autodescrição dos indivíduos. Especificamente, 322 adolescentes entre 13 e 17 anos responderam a um questionário em que se pedia que mencionassem três palavras positivas e três negativas para descreverem si mesmos. Não se tratou de avaliar a personalidade em si, mas de apreender padrões de características comuns dos participantes. A partir da análise fatorial de correspondências (AFC), surgiram fatores que opuseram os grupos dois a dois. O gênero foi o principal fator diferenciador das características citadas, mas os efeitos de ordem de nascimento também se mostraram relevantes na observação dos padrões comportamentais dos respondentes. Sugere-se que a personalidade seja pesquisada no Brasil considerando essas duas variáveis em conjunto.

Palavras-chave: Autodescrição. Gênero. Ordem de nascimento. Adolescentes.

Abstract: This article aims to communicate results and raise the researchers' interest about the gender and birth order influence in the individuals' self-description. Specifically, 322 adolescents ages 13 and 17 answered a questionnaire in which they were requested to mention three negative and three positive words best selected to describe themselves. Assessing personality itself was not the main objective, but aggregate common characteristics from the participants to draw patterns of responses. Through the correspondence factor analysis (CA), factors opposed the groups in pairs. Gender was the main variable to produce differentiation between characteristics, but birth order effects were also relevant to distinguish the patterns developed. It is suggested that personality traits should be researched in Brazil considering the combination of these two variables.

Keywords: Self-description. Gender. Birth order. Adolescents.

Resumen: Este artículo tiene como objetivo divulgar resultados y suscitar el interés de encuestadores sobre la influencia del género y de orden de nacimiento en la auto descripción de los individuos. Específicamente, 322 adolescentes entre 13 y 17 años contestaron a un cuestionario en el que se pedía que mencionasen tres palabras positivas y tres negativas que mejor describiesen a sí mismos. No se trató de evaluar la personalidad en sí, sino de aprehender calidades de características comunes de los participantes. Del análisis factorial de correspondencias (AFC), surgieron factores que opusieron los grupos dos a dos. El género fue el principal factor diferenciador de las características citadas, pero los efectos de orden de nacimiento también se mostraron relevantes en la observación de las calidades de comportamiento de los respondientes. Se sugiere que la personalidad sea investigada en Brasil considerando ésas dos variables en conjunto.

Palabras clave: Auto descripción. Género. Orden de nacimiento. Adolescentes.

O entendimento da importância da família na formação da personalidade estimulou a realização de pesquisas na área da Psicologia no intuito de conceber quais variáveis teriam maior influência na constituição dos indivíduos. Nesse sentido, dois aspectos que se mostraram de peso nesse quesito foram o gênero e a ordem de nascimento, que são tidos como dois microssistemas de interação social incluídos no sistema mais amplo a própria família - que é considerada o primeiro nicho de desenvolvimento humano. Em especial, a existência ou a ausência de irmãos durante parte ou todo o decurso da vida contribui em grande parte para a forma como nos comportamos.
É importante destacar que este artigo não pretende discutir em profundidade a diferença entre sexo e gênero, uma vez que os textos da revisão de literatura realizada não fizeram tal distinção quando trataram de tais variáveis, o que dificulta uma análise mais apurada sobre o tema neste espaço e com o material bibliográfico consultado. Contudo, utilizar-se-á, ao longo deste artigo, o conceito de gênero em detrimento do de sexo, pois o primeiro abarca fatores relacionados a diferenças socioculturais na identidade, não se restringindo ao aspecto biológico do sexo, como demarca a Psicologia social (Guedes, 1995; Manstead \& Hewstone, 1999; Matos, 2008). Tal escolha se justifica pelo propósito 
da pesquisa, que buscou a autodescrição dos participantes com relação a traços comportamentais próprios, o que implica necessariamente um posicionamento em termos de papel social relacionado ao gênero (feminino e masculino) que não se restringe à diferença física (macho e fêmea).

Além disso, a personalidade também não será tratada aqui como um construto teórico embasado em um modelo específico, pois não se objetivou avaliá-la. Este estudo apenas pesquisou a autodescrição de adolescentes, ou seja, realizou um levantamento de palavras auto-referenciadas que, segundo os próprios participantes, refletem características pessoais mais freqüentes e/ou intensas. Eysenk (1968) foi um dos maiores estudiosos do tema da personalidade, propondo que as causas comportamentais são influenciadas por fatores biológicos (hereditariedade e estruturação do sistema nervoso central e periférico) e pela interação do organismo no ambiente, e fez classificações de acordo com dois eixos principais: introversão/ extroversão e instabilidade/estabilidade. Os modelos teóricos de personalidade, porém, são diversos, e não se limitam a esses fatores. Assim, vale ressaltar que a personalidade será entendida aqui como um conjunto de traços comportamentais estáveis apresentados pelos indivíduos, sem se restringir a uma definição específica. Espera-se que dos resultados desta pesquisa possam derivar futuros estudos de modo mais aprofundado sobre personalidade, especialmente levando em conta o gênero e a ordem de nascimento dos indivíduos.

Estudos sugerem que o gênero e a ordem de nascimento podem explicar porque algumas pessoas apresentam comportamentos mais estáveis e freqüentes do que outras. Segundo essa idéia, a relação entre irmãos seria mais influente na definição dos padrões comportamentais do que a própria relação dos filhos com os pais. Tal diferença se deveria, principalmente, à competição pelo amor parental, segundo o qual os filhos se diferenciam no decurso de seu desenvolvimento aprendendo quais as formas mais funcionais de chamar a atenção dos pais. Outras diferenças seriam justificadas pelo desenvolvimento de estratégias funcionais de adaptação que os irmãos utilizam para lidarem um com o outro no sistema interno da fratria (Fernandes, Alarcão, \& Raposo, 2007; Isaacson \& Radish, 2002; Sulloway, 1996).

Uma pesquisa sobre personalidade desenvolvida por Ernst e Angst (1983) sugeriu que a ordem de nascimento é um fator mais determinante da personalidade do que o gênero. No entanto, quando tomados conjuntamente, gênero e ordem de nascimento ganham ainda mais força na explicação dos comportamentos, ou seja, os efeitos da ordem de nascimento são potencializados pelo gênero do indivíduo, e vice-versa. Um exemplo de pesquisa de interação entre gênero e ordem de nascimento foi desenvolvida por Ickes e Turner (1983), em cujo trabalho foram comparadas 40 díades de irmãos de sexos opostos. Os resultados indicaram que os homens caçulas se expressavam em média duas vezes mais do que os primogênitos, fazendo perguntas, olhando no olho ao falar, reforçando verbalmente o interlocutor e falando mais sobre si mesmos. Da mesma forma, as caçulas tiveram mais iniciativa de interação do que as primogênitas.

Outro estudo mais recente (Fernandes et al., 2007) também demonstrou diferenças de personalidade devido à ordem de nascimento. Os autores aplicaram o inventário NEO Personality Inventory Revised (NEO PI-R) em uma amostra de 1142 (76,5\% do sexo feminino) universitários em Portugal. O NEO PI-R é um instrumento de avaliação de personalidade que segue um modelo que contém cinco fatores explicativos: neuroticismo, extroversão, 
Segundo

Sulloway (1996),

a receptividade da inovação científica e das teorias liberais, mesmo dentre várias classes sociais, é maior para irmãos mais novos. abertura à experiência, amabilidade e conscienciosidade. Como resultado, os autores chegaram a três diferenças estatisticamente significativas entre os grupos pesquisados. A primeira delas diferenciou os filhos únicos dos primogênitos e caçulas. Os filhos únicos se mostraram menos amáveis do que os demais, os primogênitos mais complacentes (capazes de perdoar, esquecer, aceitar opinião alheia) do que os únicos, e os caçulas mais retos (francos, frontais, diretos, sinceros e ingênuos ao lidar com os outros). Na segunda, os primogênitos apresentaramse mais conscienciosos, ou seja, mais obedientes ao dever, mais deliberados, mais altruístas e menos hostis do que os irmãos do meio. E a terceira demonstrou que os caçulas são mais retos e complacentes do que os irmãos do meio.

Segundo Sulloway (1996), a receptividade da inovação científica e das teorias liberais, mesmo dentre várias classes sociais, é maior para irmãos mais novos. Para ele, isso ocorre porque é natural os primogênitos se identificarem mais fortemente com poder e autoridade, impondo seu tamanho e força para defender seu status especial. O autor teoriza que os primogênitos são mais autoconfiantes, usam mais seu tamanho e força para defender seus interesses, são mais propensos a cumprir a expectativa dos pais e prontos para aceitar sua autoridade, sendo mais responsáveis, mais ansiosos e emocionalmente intensos. Assim, são mais conformados, convencionais e menos abertos a mudanças.

Os mais novos, por sua vez, são mais inclinados a questionar o status quo e, em alguns casos, a desenvolver uma personalidade revolucionária. Eles tendem a desfavorecer a comparação com irmãos mais velhos, buscando desenvolver um atributo pessoal diferente dos outros irmãos de modo a se destacar no sistema fraterno.
Essa busca favorece o desenvolvimento da criatividade e realça a abertura a novas experiências, podendo suscitar um espírito aventureiro e rebelde, maior aceitação de riscos e apoio a mudanças sociais igualitárias. Os filhos do meio, quando comparados aos demais, demonstram ser mais flexíveis e comprometidos, ter mais habilidades diplomáticas e aceitar coalizões com os irmãos, sabendo dividir melhor o poder.

Por sua vez, Isaacson e Radish (2002) categorizaram os tipos de personalidade, segundo a ordem de nascimento, em cinco grandes grupos. Os autores ressaltam que não necessariamente a ordem cronológica de nascimento seja a mesma da "ordem de personalidade", mas que, de modo geral, existem padrões de comportamentos para cada uma das posições. Segundo eles, os tipos de personalidade são: filho único, primogênito, nascido em segundo, nascido em terceiro e nascido em quarto lugares.

Para os autores, o modelo de filho único apresenta, principalmente, traços ligados à organização de tarefas, preocupação emocional e necessidade de ter tempo para si mesmo. O primogênito, ao sentimento de culpa, à inexpressão emocional e ao comprometimento com suas responsabilidades. O nascido em segundo lugar, à exigência perfeccionista, ao sentimento de raiva e a ser mais prestativo. $\mathrm{O}$ nascido em terceiro lugar, à vulnerabilidade, à criatividade e aos sentimentos de ansiedade, e o nascido em quarto lugar, por fim, ao sentimento de exclusão, imaturidade e à exigência com relação ao trabalho.

Para Sulloway (1996) e Isaacson e Radish (2002), a ordem de nascimento não é uma determinante rígida da personalidade, mas sua influência pode ser mais forte do que a literatura da Psicologia divulga usualmente. Os autores concordam que as personalidades segundo a ordem de nascimento são mais 
visíveis em famílias menos harmoniosas, ou seja, em que há mais conflito, abuso, negligência, uso de substâncias tóxicas e comportamentos inadequados dos pais, como superproteção, controle inconsistente, punição freqüente e exigências incoerentes com relação aos filhos. Vale lembrar que a diferença de idade entre os irmãos também é um fator relevante, visto que um primogênito é criado e se mantém como filho único até o nascimento dos outros filhos. Isso também pode ocorrer com as demais ordens. Além disso, para os autores, o gênero do filho interage com a ordem de nascimento, mas não é um fator tão forte quanto ela na contribuição de aspectos comportamentais, pois a percepção da preferência e a ameaça de perda de amor parental, ou seja, a competição fraterna, ocorre independentemente do sexo do irmão.

Ainda assim, diferenças de comportamentos atribuídas ao gênero compõem um tema mais pesquisado e divulgado cientificamente do que a ordem de nascimento, estando presente especialmente em teorias de esquemas de gênero e de papéis sociais. Em um estudo desenvolvido com adolescentes, Feingold (1994) relacionou variáveis sociais e de personalidade observadas com maior freqüência em grupos masculinos e femininos. Como resultado, o autor observou que as meninas se mostraram mais ansiosas, impulsivas, gregárias, confiáveis, delicadas e conscienciosas, e os meninos mais assertivos, ativos e abertos a novas experiências. Também Ribeiro (1988), estudando o autoconceito de adolescentes, relatou que o gênero influenciou o fator ético-moral dos participantes, sendo a característica de moralidade mais presente nas meninas.

Giavoni e Tamayo (2000), baseados na teoria de auto-esquemas, construíram duas escalas referentes aos componentes do autoconceito - os esquemas masculino e feminino. Não se tratou de diferenciar traços de personalidade de homens e mulheres, mas de atribuir componentes masculinos e femininos utilizados pelas pessoas para se autodescreverem, independentemente do sexo biológico. Para a escala feminina, as principais características foram: tolerância (compreender e aceitar as necessidades alheias), insegurança (medo da rejeição, timidez, introversão), sensualidade (preocupação com imagem, aparência), emotividade (livre expressão de sentimentos), responsabilidade (cumprir deveres e normas sociais) e sensibilidade (reúne os fatores: tolerância, emotividade e responsabilidade). Para o grupo masculino, foram: negligência (irresponsabilidade, despreocupação), racionalidade (realista, objetivo), ousadia (busca de algo novo e inusitado), agressividade (controle) e indiferença (reúne os fatores: negligência e agressividade). Os autores ressaltam que a presença desses dois esquemas no autoconceito dos indivíduos deixa de dicotomizar os conceitos de masculinidade e feminilidade. No entanto, eles consideram que as estruturas fatoriais dos esquemas masculino e feminino diferem de acordo com o sexo, em uma tendência em que as mulheres apresentam mais traços do esquema feminino, e os homens, do esquema masculino de forma mais proeminente.

Sobre semelhanças e diferenças de gênero, um artigo produzido por Hyde (2005) postula a hipótese de similaridade dos sexos. A despeito de várias publicações que reforçam a idéia de que homens e mulheres apresentam características bastante peculiares e até opostas, a autora rebate afirmando que pouco é comprovado nesse sentido. A partir de uma metanálise, ela ressalta que as únicas diferenças reais entre os sexos se mantêm nos aspectos da sexualidade, agressividade e comportamento motor, sendo tais quesitos mais presentes nos homens. A autora sustenta que as pesquisas que apontam diferenças entre os gêneros não podem desconsiderar o 
contexto em que são desenvolvidas, visto que os papéis sociais são aprendidos culturalmente. Assim, os estereótipos sexuais são conceitos criados pelas sociedades, podendo diferenciar-se entre elas, e quando homens e mulheres são "despidos" desses conceitos de gênero, pouca diferença resiste entre eles.

A partir desse breve panorama, observa-se que a quantidade das pesquisas realizadas não se mostra suficiente para responder como ocorre a influência do gênero e da ordem de nascimento na personalidade ou na autodescrição dos indivíduos. A divulgação de resultados por vezes contraditórios e passíveis de questionamentos, especialmente no que concerne ao método por elas administrado, contribui para a inconsistência. No entanto, a falta de concordância entre pesquisadores não deve ser tomada como algo prejudicial à construção teórica, e sim, como um aspecto do próprio objeto de estudo, que se mostra de difícil apreensão operacional. Deve ser tomada, inclusive, como estímulo à realização de novas pesquisas, pois o próprio contexto de atuação da Psicologia é sistêmico e dinâmico, devendo sempre ser atualizado. Com isso em vista, o presente artigo pretende contribuir para os estudos de desenvolvimento humano, sinalizando possíveis vieses de autodescrição adotados por adolescentes dependendo do gênero e da ordem de nascimento dos adolescentes.

\section{Método e procedimentos}

Participantes: 322 adolescentes entre 13 e 17 anos (média de 14 anos e 6 meses), 59\% do sexo feminino, estudantes da $8^{\underline{a}}$ série do ensino fundamental, $1^{\circ}$ e $2^{\circ}$ anos do ensino médio. A maioria dos estudantes (68,9\%) mora com os pais, cuja escolaridade foi, na maioria, curso superior, completo ou não (55,6\%). Visto o interesse da pesquisa em avaliar características segundo o gênero e a ordem de nascimento, estão expostos na Tabela 1 os grupos que constituíram a amostra de acordo com essas variáveis.

Tabela 1.Distribuição dos participantes nos grupos segundo gênero e ordem de nascimento.

\begin{tabular}{lllll}
\hline & \multicolumn{3}{l}{ Sexo } \\
\hline Grupos & \multicolumn{2}{l}{ Feminino } & \multicolumn{2}{l}{ Masculino } \\
\hline Primogênitos & $\mathrm{n}$ & $\%$ & $\mathrm{n}$ & $\%$ \\
Do meio & 64 & 33,7 & 51 & 38,6 \\
Caçula & 32 & 16,8 & 17 & 12,9 \\
Únicos & 64 & 33,7 & 49 & 37,1 \\
Total & 30 & 15,8 & 15 & 11,4 \\
\hline
\end{tabular}

A amostra pode ser considerada homogênea do ponto de vista da fase de desenvolvimento dos respondentes, devido à idade da maioria e da configuração familiar, pois a maior parte deles enquadra-se no modelo de família nuclear. A escolaridade dos pais, embora possa ser um fator importante para a adoção de um ou outro modelo educativo, não foi aprofundada em pormenores nesta pesquisa, justamente por ter assumido uma distribuição bastante concentrada em um tipo, o ensino superior, não sendo adequado fazer comparações com as demais para não se tomar conclusões precipitadas. 
Por outro lado, embora a renda não tenha sido requisitada nesta pesquisa, sabe-se que ela foi um fator variante dentre os participantes, pois metade da amostra $(50,6 \%)$ é estudante de um colégio particular da cidade de Curitiba, enquanto $26,7 \%$ deles estudam em uma escola estadual e $22,7 \%$, apesar de estudarem em escolas particulares, o fazem porque recebem bolsa de uma instituição por terem renda familiar entre um e quatro salários-mínimos.

Instrumento: como este artigo é parte de uma pesquisa mais ampla, foi utilizado um questionário desenvolvido pelos pesquisadores a fim de coletar palavras (descritores) utilizadas pelos adolescentes. Para tanto, na última questão do referido questionário, pediu-se que os participantes escrevessem nas linhas ofertadas três palavras positivas (item características positivas) e três negativas (item características negativas) consideradas adequadas para sua autodescrição. Apenas palavras, não frases. A consigna foi "Escreva três características suas que considere positivas e três que considere negativas".

Coleta de dados: os dados foram coletados através do referido questionário, que foi aplicado coletivamente em sala de aula de três instituições de ensino de Curitiba, PR (uma escola estadual, uma particular e uma organização não-governamental) após a devida permissão da direção e agendamento com os professores. Foi exigida a assinatura dos pais nos Termos de Consentimento Livre e Esclarecido (TCLE) permitindo a participação dos filhos na pesquisa; os alunos cujos TCLEs não estavam assinados não puderam participar.

Análise dos dados: tendo em mãos as palavras citadas, foi realizada a análise fatorial de correspondências (AFC) através do software francês SPAD (systéme portable pour I'analyse de donnés textualles), cujo objetivo é "representar um dado conjunto de variáveis através de um menor número de variáveis hipotéticas, ou fatores, que garantam a maior covariação das variáveis observadas. Os fatores resultam da combinação linear dessas variáveis e permitem dar sentido às combinações obtidas e às variáveis que as constituem" (Oliveira \& Amâncio, 2005, p. 327). Foi feita uma AFC para o item "características positivas" e outra para "características negativas". Na primeira, consideraram-se as palavras cuja contribuição foi igual ou acima de 2,2, e, na segunda, igual ou acima de 2,3, valores que foram as respectivas médias.

O projeto da pesquisa foi submetido ao Comitê de Ética da Universidade Federal de Santa Catarina, seguindo as normas da Resolução no 196/96, do Conselho Nacional de Ética em Pesquisa, e recebeu aprovação sob o no 026/07.

\section{Resultados e discussão}

A partir da análise fatorial de correspondência (AFC), tanto para características positivas (Tabela 2), quanto negativas (Tabela 3), foram obtidos quatro fatores. Para ambas, o primeiro fator de diferenciação foi o gênero. Isso indica que, em termos de autodescrição, as palavras utilizadas por meninos e meninas diferenciaram-se com maior freqüência, sugerindo que os papéis sociais definidos pelo gênero parecem ser mais fortes do que os da ordem de nascimento. Para as características positivas, o primeiro e o segundo fatores foram responsáveis por $67,12 \%$ da inércia total; para as negativas, os mesmos fatores somaram $65,85 \%$. Por serem os fatores de maior contribuição, apenas eles foram considerados nas Figuras 1 e 2 . 
Tabela 2. Análise fatorial de correspondências para características positivas.

\begin{tabular}{|c|c|c|c|c|c|c|c|c|}
\hline \multirow[t]{2}{*}{ Fator } & \multicolumn{4}{|c|}{ De fora para dentro } & \multicolumn{3}{|c|}{ De dentro para fora } & \multirow[b]{2}{*}{ Cos2 } \\
\hline & Modalidades & Coord. & $\mathrm{CPF}$ & Cos2 & Modalidades & Coord. & $\mathrm{CPF}$ & \\
\hline \multirow[t]{2}{*}{ Primeiro, } & Masculino & $-0,46$ & 58,4 & 0,98 & Feminino & 0,29 & 36,9 & 0,98 \\
\hline & Elementos & Coord. & CPF & Cos2 & Elementos & Coord. & $\mathrm{CPF}$ & Cos2 \\
\hline \multirow{7}{*}{$\begin{array}{l}\text { Autovalor }= \\
0,07 \\
\text { Inércia = } \\
46,48 \%\end{array}$} & Bom & $-0,98$ & 6,9 & 0,8 & Confiável & 0,36 & 2,6 & 0,64 \\
\hline & Bonito & $-0,76$ & 11,3 & 0,9 & Otimista & 0,64 & 7,3 & 0,77 \\
\hline & Engraçado & $-0,22$ & 2,5 & 0,25 & Persistente & 0,30 & 2,6 & 0,92 \\
\hline & Esperto & $-0,90$ & 8,9 & 0,87 & Sincero & 0,27 & 7,1 & 0,75 \\
\hline & Fiel & $-0,90$ & 7,4 & 0,54 & & & & \\
\hline & Inteligente & $-0,36$ & 10,6 & 0,91 & & & & \\
\hline & Legal & $-0,37$ & 5,5 & 0,51 & & & & \\
\hline
\end{tabular}

\begin{tabular}{llrrrlcrl}
\hline & \multicolumn{3}{c}{ Conversador } & \multicolumn{3}{c}{ Engraçado } \\
\hline Segundo, & Único & $-0,53$ & 58,6 & 0,72 & Caçula & 0,19 & 21,1 & 0,35 \\
\cline { 2 - 9 } & lementos & Coord. & CPF & Cos2 & Elementos & Coord. & CPF & Cos2 \\
\cline { 2 - 9 } & Amoroso & $-0,27$ & 2,9 & 0,22 & Brincalhão & 0,26 & 2,8 & 0,34 \\
Autovalor $=$ & Compreensivo & $-0,32$ & 8,4 & 0,66 & Carinhoso & 0,21 & 4,7 & 0,39 \\
0,03 & Confiante & $-0,76$ & 11,8 & 0,86 & Divertido & 0,21 & 3,1 & 0,51 \\
$20,64 \%$ & Conversador & $-0,74$ & 13,4 & 0,81 & Engraçado & 0,29 & 10,2 & 0,46 \\
& Criativo & $-0,38$ & 4,6 & 0,74 & Espontâneo & 0,30 & 2,5 & 0,66 \\
& Otimista & $-0,30$ & 3,7 & 0,17 & Respeitoso & 0,28 & 2,9 & 0,51 \\
& & & & & Responsável & 0,25 & 2,6 & 0,36
\end{tabular}

\begin{tabular}{|c|c|c|c|c|c|c|c|c|}
\hline \multirow[b]{2}{*}{ Terceiro, } & \multirow[b]{2}{*}{ Caçula } & \multicolumn{3}{|c|}{ Divertido } & \multicolumn{3}{|c|}{ Companheiro } & \multirow[b]{2}{*}{0,78} \\
\hline & & $-0,25$ & 40,6 & 0,6 & Primogênito & 0,29 & 53,7 & \\
\hline \multirow{9}{*}{$\begin{array}{l}\text { Autovalor }= \\
0,0274 \\
\text { Inércia = } \\
18,39 \%\end{array}$} & Elementos & Coord. & CPF & $\operatorname{Cos} 2$ & Elementos $\mathrm{C}$ & Coord. & CPF & Cos2 \\
\hline & Amigo & $-0,13$ & 6,4 & 0,46 & Amoroso & 0,45 & 9,1 & 0,6 \\
\hline & Calmo & $-0,27$ & 3,9 & 0,42 & Brincalhão & 0,27 & 3,4 & 0,37 \\
\hline & Confiável & $-0,23$ & 2,8 & 0,27 & Companheiro & 0,27 & 11,2 & 0,98 \\
\hline & Engraçado & $-0,22$ & 6,4 & 0,26 & Comunicativo & 0,64 & 7,4 & 0,67 \\
\hline & Legal & $-0,26$ & 7,0 & 0,26 & Determinado & 0,32 & 3,3 & 0,61 \\
\hline & Responsável & $-0,27$ & 3,4 & 0,43 & Feliz & 0,23 & 3,9 & 0,54 \\
\hline & Simpático & $-0,12$ & 2,9 & 0,30 & Paciente & 0,44 & 3,6 & 0,46 \\
\hline & & & & & Sincero & 0,15 & 5,3 & 0,22 \\
\hline & & \multicolumn{3}{|c|}{ Honesto } & & Fiel & & \\
\hline \multirow[t]{3}{*}{ Quarto, } & Único & $-0,30$ & 25,9 & 0,22 & Do meio & 0,43 & 69,8 & 0,78 \\
\hline & Elementos & Coord. & $\mathrm{CPF}$ & Cos2 & Elementos & Coord. & CPF & Cos2 \\
\hline & Bonito & $-0,22$ & 3,1 & 0,08 & Atencioso & 0,33 & 7,7 & 0,52 \\
\hline \multirow{5}{*}{$\begin{array}{l}\text { Autovalor= } \\
0,0216 \\
\text { Inércia= } \\
14,49 \%\end{array}$} & Calmo & $-0,28$ & 5,6 & 0,47 & Bem-humorado & o 0,16 & 3,1 & 0,25 \\
\hline & Comunicativo & $-0,41$ & 3,8 & 0,27 & Esperto & 0,33 & 3,8 & 0,12 \\
\hline & Conversador & $-0,32$ & 3,7 & 0,16 & Estudioso & 0,29 & 7,8 & 0,89 \\
\hline & Honesto & $-0,34$ & 9,9 & 0,51 & Fiel & 0,76 & 16,9 & 0,39 \\
\hline & Legal & $-0,25$ & 8,0 & 0,23 & Gentil & 0,64 & 9,5 & 0,88 \\
\hline
\end{tabular}


O primeiro fator das características positivas contrapôs os gêneros (masculino $x$ feminino), sendo responsável por quase $47 \%$ da contribuição total. As palavras citadas com mais freqüência pelos meninos foram bonito e inteligente, enquanto, pelas meninas, foram otimista e sincero. Observando o padrão de respostas de cada gênero, percebe-se que o lócus da escolha das palavras é diferente. Para os meninos, as palavras mais freqüentes denotam racionalidade, característica que aparece no esquema masculino de Giavoni e Tamayo (2000), pois remetem a características objetivas, claras, com certo distanciamento emocional. As meninas, por sua vez, crêem ser mais otimistas e sinceras, descritores relacionados à maior emotividade e tolerância, fatores correspondentes ao esquema feminino de autoconceito proposto pelos mesmos autores.

O segundo fator diferenciou os padrões de resposta de filhos únicos e caçulas. Para os primeiros, as palavras mais freqüentes foram conversador e confiante; para os segundos, a principal foi engraçado, e marcou grande diferença das demais. A Figura 1 mostra a disposição gráfica do cruzamento dos fatores 1 e 2.

Fator 2

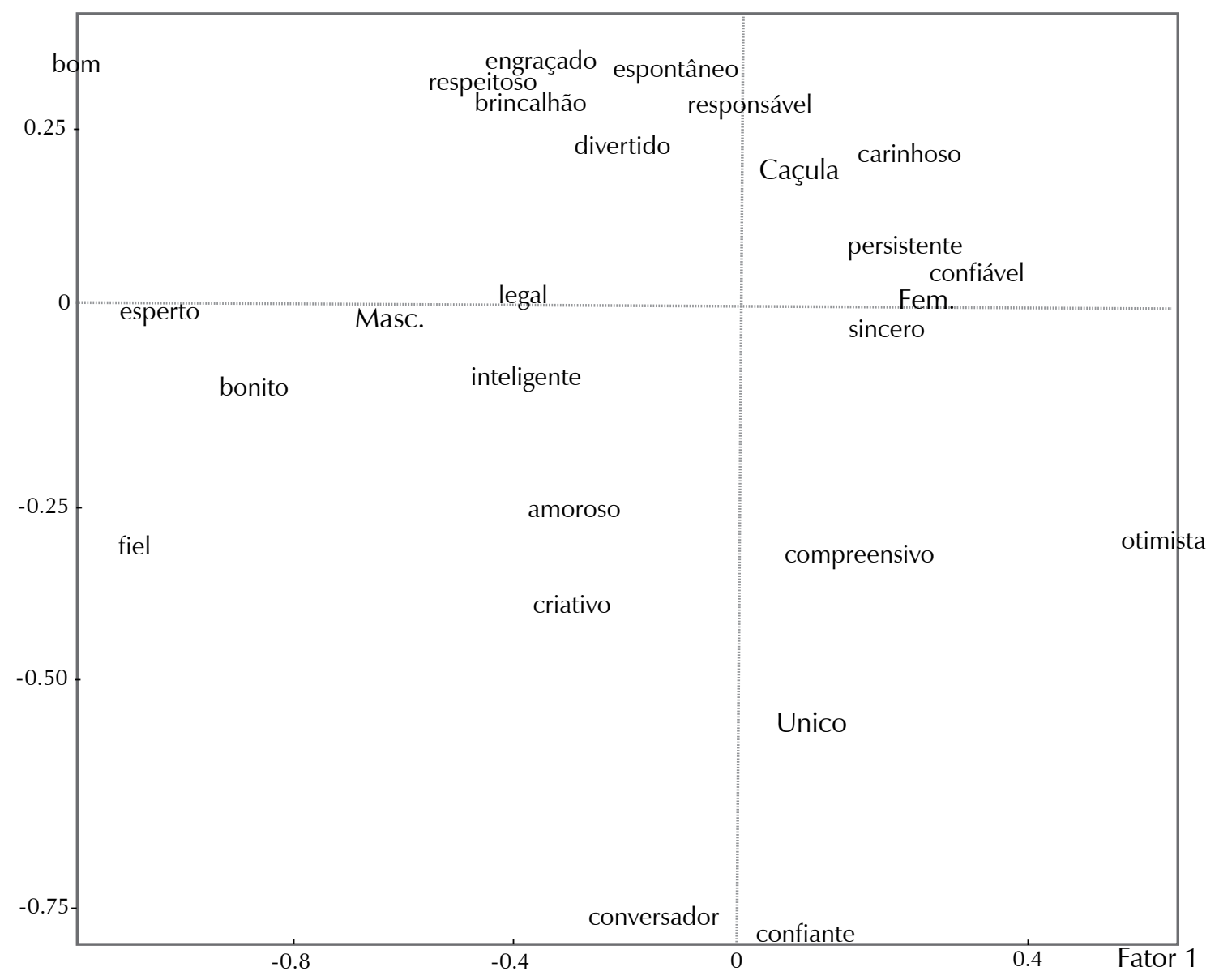

Figura 1. Disposição gráfica dos dois primeiros fatores da análise de correspondências para características positivas.

Observa-se, pela Figura 1, que as palavras descritoras dos meninos e dos filhos únicos estão mais dispersas no gráfico, o que sugere maior variabilidade de citações. As palavras referentes às meninas e aos caçulas estão mais próximas, o que indica que foram respondidas pelas mesmas pessoas. Especificamente, a característica ser otimista foi mais freqüente para filhas únicas, e engraçado, para meninos caçulas. Percebe-se que essas palavras referidas no segundo fator 
sugerem que os filhos únicos têm certa habilidade social, ao menos ao conversar, e se mostram mais autoconfiantes do que os caçulas. Os caçulas, por sua vez, consideram-se engraçados, característica que também surgiu na sua comparação com os primogênitos, no terceiro fator.

O terceiro fator opôs primogênitos e caçulas. Os caçulas mantiveram o mesmo tipo de resposta do segundo fator, ou seja, caracterizam-se como divertidos, tendo sido citadas as palavras legal, amigo e engraçado em maior e quase igual freqüência. Os primogênitos, por sua vez, caracterizaram-se pelas palavras companheiro e amoroso, e, em menor escala, comunicativo. A característica de divertimento, portanto, foi diferencial para os caçulas ao serem comparados aos filhos únicos e primogênitos.

Segundo Sulloway (1996) e Isaacson e Radish (2002), os primogênitos e os filhos únicos podem apresentar características parecidas, porque os primeiros passam pela experiência dos segundos até o nascimento do(s) irmão(s). Para eles, os primogênitos são mais autoconfiantes e hábeis socialmente do que os irmãos mais novos. Isso também foi sugerido por esses resultados. Os mais novos, todavia, são mais abertos a novas experiências e mais criativos ao pensarem em estratégias competitivas para serem favorecidos; nesse sentido, o fato de se considerarem divertidos pode ser uma forma particular de eles se comportarem. Também para Herrera, Zajonc, Wieczorkowska e Cichomski (2003), os caçulas são mais criativos, emotivos e extrovertidos.

O quarto fator diferenciou os filhos únicos dos filhos do meio, em que os primeiros se julgaram honestos e legais, e os segundos, fiéis, sendo essa característica (fidelidade) muito mais freqüente do que as demais para o mesmo grupo. O padrão de elementos utilizados pelos primeiros denota habilidade comunicativa, por se auto-afirmarem calmos, comunicativos e conversadores. Os filhos do meio também sugerem ter competências sociais nesse fator, entretanto, de outra forma. As palavras escolhidas (fiel, gentil, atencioso) sugerem uma preocupação em agradar os outros, no sentido de corresponder a expectativas, em ser cooperativo. Para Sulloway (1996), os filhos do meio são mais flexíveis e comprometidos, demonstrando ter habilidades diplomáticas, e, para Isaacson e Radish (2002), os nascidos em segundo e terceiro lugares (que equivalem aos do meio, nessa pesquisa) são amigáveis e prestativos.

A análise fatorial para as características negativas gerou fatores parecidos, com exceção daquele formado pela comparação entre primogênitos e caçulas para características positivas, que deu lugar à oposição entre primogênitos e filhos do meio.

O primeiro fator das características negativas também foi o gênero, responsável por quase $40 \%$ da inércia total. A palavra mais citada pelo grupo masculino foi pentelho, que indica perturbar, incomodar os outros com certa freqüência e intensidade. Essa palavra ficou bem acima da média das demais da modalidade, o que sugere que ela tem grande força descritora para os meninos. As meninas, por sua vez, julgam que suas características negativas mais proeminentes são ser egoístas e orgulhosas. Novamente, o ponto de vista utilizado por meninos e meninas variou. Os primeiros parecem corresponder mais ao fator indiferença (que agrupa negligência e agressividade) do esquema masculino de Giavoni e Tamayo (2000), já que têm uma tendência a desconsiderar o alheio para conseguir o que querem, indicando isso através das palavras pentelho, folgado e grosso. Já as meninas indicam ter maior sensibilidade na sua autodescrição, fator que engloba preocupação com o bem-estar dos outros, livre expressão de emoções, compartilhamento e comprometimento afetivos e cumprimento de deveres. Isso pode ser notado por elas considerarem que o fato de não serem altruístas e humildes (contrário das palavras citadas) são pontos negativos da personalidade (Tabela 2). 
Tabela 3 - Análise fatorial de correspondências para características negativas.

\begin{tabular}{|c|c|c|c|c|c|c|c|c|}
\hline \multirow[t]{2}{*}{ Fator } & \multicolumn{4}{|c|}{ De fora para dentro } & \multicolumn{2}{|c|}{ De dentro para fora } & \multirow[b]{2}{*}{ CPF } & \multirow[b]{2}{*}{$\operatorname{Cos}^{2}$} \\
\hline & Modalidades & Coord. & CPF & $\operatorname{Cos}^{2}$ & Modalidades & Coord. & & \\
\hline \multirow[t]{5}{*}{ Primeiro, } & Masculino & $-0,43$ & 48,5 & 0,81 & Feminino & 0,22 & 25,4 & 0,81 \\
\hline & Elementos & Coord. & CPF & $\operatorname{Cos}^{2}$ & Elementos & Coord. & $\mathrm{CPF}$ & $\operatorname{Cos}^{2}$ \\
\hline & Bagunceiro & $-0,40$ & 2,9 & 0,64 & Egoísta & 0,46 & 6,5 & 0,70 \\
\hline & Burro & $-0,64$ & 3,8 & 0,29 & Estressado & 0,22 & 3,8 & 0,43 \\
\hline & Chato & $-0,17$ & 2,7 & 0,47 & Impaciente & 0,23 & 3,1 & 0,66 \\
\hline \multirow{7}{*}{$\begin{array}{l}\text { Autovalor = } \\
0,065 \\
\text { Inércia = } \\
38,86 \%\end{array}$} & Desorganizado & $-0,24$ & 2,4 & 0,43 & Impulsivo & 0,53 & 3,3 & 0,52 \\
\hline & Esquecido & $-0,57$ & 3,7 & 0,86 & Irresponsável & 0,39 & 2,9 & 0,55 \\
\hline & Folgado & $-0,60$ & 5,0 & 0,45 & Orgulhoso & 0,58 & 6,3 & 0,86 \\
\hline & Grosso & $-0,42$ & 5,7 & 0,80 & Pessimista & 0,47 & 3,0 & 0,41 \\
\hline & Mentiroso & $-0,44$ & 2,3 & 0,57 & Sensível & 0,43 & 2,6 & 0,36 \\
\hline & Pentelho & $-1,14$ & 15,0 & 0,91 & & & & \\
\hline & Preguiçoso & $-0,19$ & 4,6 & 0,88 & & & & \\
\hline
\end{tabular}

\begin{tabular}{|c|c|c|c|c|c|c|c|c|}
\hline \multirow[b]{2}{*}{ Segundo, } & \multicolumn{4}{|c|}{ Contraditório } & \multicolumn{2}{|c|}{ Introspectivo } & \multirow[b]{2}{*}{18,9} & \multirow[b]{2}{*}{0,32} \\
\hline & Do meio & $-0,45$ & 36,2 & 0,49 & Único & 0,37 & & \\
\hline \multirow{10}{*}{$\begin{array}{l}\text { Autovalor = } \\
0,045 \\
\text { Inércia= } \\
26,99 \%\end{array}$} & Elementos & Coord. & $\mathrm{CPF}$ & $\operatorname{Cos}^{2}$ & Elementos & Coord. & $\mathrm{CPF}$ & $\operatorname{Cos}^{2}$ \\
\hline & Burro & $-0,94$ & 11,9 & 0,63 & Desorganizado & 0,26 & 4,0 & 0,50 \\
\hline & Crítico & $-0,32$ & 2,8 & 0,20 & Insistente & 0,49 & 8,8 & 0,95 \\
\hline & Desatento & $-0,54$ & 7,9 & 0,62 & Irritado & 0,30 & 6,9 & 0,69 \\
\hline & Egoísta & $-0,28$ & 3,5 & 0,26 & Teimoso & 0,19 & 4,3 & 0,64 \\
\hline & Estúpido & $-0,42$ & 2,4 & 0,37 & Tímido & 0,28 & 8,9 & 0,98 \\
\hline & Folgado & $-0,38$ & 2,9 & 0,18 & & & & \\
\hline & Impulsivo & $-0,51$ & 4,3 & 0,47 & & & & \\
\hline & Mal-humorado & $-0,21$ & 5,0 & 0,36 & & & & \\
\hline & Metido & $-0,80$ & 10,7 & 0,75 & & & & \\
\hline
\end{tabular}

\begin{tabular}{|c|c|c|c|c|c|c|c|c|}
\hline \multirow{3}{*}{ Terceiro, } & \multicolumn{4}{|c|}{ Mal-humorado } & \multicolumn{3}{|c|}{ Crítico } & \\
\hline & Primogênito & $-0,29$ & 48,7 & 0,69 & Do meio & 0,37 & 34,4 & 0,32 \\
\hline & Elementos & Coord. & CPF & $\operatorname{Cos}^{2}$ & Elementos & Coord. & CPF & $\operatorname{Cos}^{2}$ \\
\hline \multirow{7}{*}{$\begin{array}{l}\text { Autovalor }= \\
0,0313 \\
\text { Inércia }= \\
18,77 \%\end{array}$} & Ciumento & $-0,33$ & 9,0 & 0,66 & Bagunceiro & 0,25 & 2,4 & 0,26 \\
\hline & Desatento & $-0,33$ & 4,3 & 0,24 & Brabo & 0,21 & 2,3 & 0,24 \\
\hline & Exigente demais & $-0,36$ & 4,3 & 0,82 & Chorão & 0,50 & 4,8 & 0,34 \\
\hline & Folgado & $-0,50$ & 7,1 & 0,31 & Crítico & 0,60 & 14,1 & 0,70 \\
\hline & Mal-humorado & $-0,26$ & 10,8 & 0,54 & Estúpido & 0,45 & 3,8 & 0,42 \\
\hline & Pessimista & $-0,33$ & 3,1 & 0,20 & Sensível & 0,50 & 7,4 & 0,50 \\
\hline & & & & & Temperamental & 0,30 & 3,8 & 0,59 \\
\hline
\end{tabular}

\begin{tabular}{|c|c|c|c|c|c|c|c|c|}
\hline \multirow{2}{*}{ Quarto, } & \multicolumn{4}{|c|}{ Desobediente } & \multicolumn{4}{|c|}{ Pessimista } \\
\hline & Único & $-0,52$ & 66,9 & 0,65 & Caçula & 0,18 & 21,3 & 0,21 \\
\hline \multirow{10}{*}{$\begin{array}{l}\text { Autovalor = } \\
0,0256 \\
\text { Inércia }= \\
15,39 \%\end{array}$} & Elementos & Coord. & CPF & $\operatorname{Cos}^{2}$ & Elementos & Coord. & CPF & $\operatorname{Cos}^{2}$ \\
\hline & Ansioso & $-0,16$ & 2,8 & 0,73 & Brabo & 0,20 & 2,6 & 0,22 \\
\hline & Briguento & $-0,17$ & 3,5 & 0,96 & Irresponsável & 0,27 & 3,5 & 0,27 \\
\hline & Chato & $-0,17$ & 6,8 & 0,47 & Orgulhoso & 0,22 & 2,3 & 0,12 \\
\hline & Desatento & $-0,23$ & 2,6 & 0,12 & Pentelho & 0,34 & 3,3 & 0,08 \\
\hline & Desobediente & $-0,52$ & 9,5 & 0,60 & Perfeccionista & 0,25 & 3,4 & 0,52 \\
\hline & Estressado & $-0,21$ & 9,3 & 0,42 & Pessimista & 0,41 & 6,0 & 0,32 \\
\hline & Irritado & $-0,17$ & 4,0 & 0,23 & Preocupado & 0,28 & 2,3 & 0,38 \\
\hline & & & & & Respondão & 0,30 & 4,7 & 0,97 \\
\hline & & & & . & Vingativo & 0,39 & 4,4 & 0,56 \\
\hline
\end{tabular}


O segundo fator contrapôs os filhos do meio aos únicos, sendo que as palavras mais freqüentes para os primeiros foram burro e metido, e, para os segundos, tímido e insistente. Para o grupo dos filhos do meio, os elementos foram mais dispersos e apareceram em maior quantidade, o que dificulta a visualização de um padrão de respostas. De forma um tanto extrema, parece que esse grupo se dividiu entre aqueles que se consideram desfavorecidos intelectualmente (palavras burro e desatento) e aqueles que denotam certo ar de superioridade, os que se julgam metidos, egoístas e estúpidos. Os elementos do grupo dos filhos únicos, porém, tiveram uma distribuição mais homogênea. Mesmo assim, a formação dos elementos ficou confusa, pois, ao mesmo tempo em que os filhos únicos relataram ter certa habilidade social nas características positivas, eles assinalaram ser tímidos, irritados (e não calmos) e teimosos. Por outro lado, Sulloway (1996) também destaca que os filhos únicos e os filhos mais novos são mais tímidos quando comparados aos primogênitos, até por terem menor habilidade social. A Figura 2 apresenta o cruzamento dos fatores 1 e 2 .

Fator 2

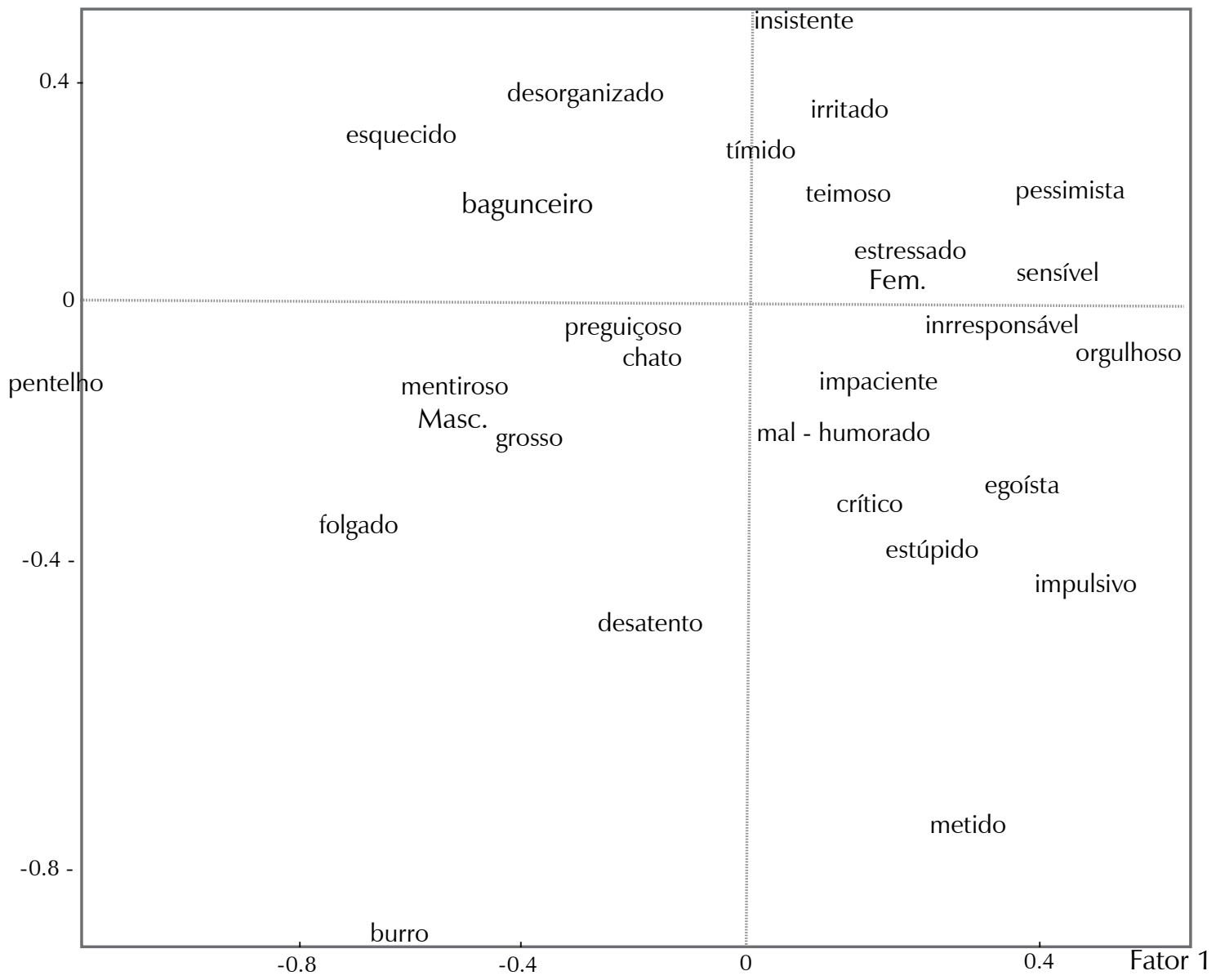

Figura 2. Disposição gráfica dos dois primeiros fatores da análise de correspondências para características negativas.

A partir da Figura 2, observam-se facilmente as diferenças de gênero, pois as palavras mentiroso, grosso e folgado estão muito próximas do grupo masculino, e as palavras estressado, pessimista e sensível, mais próximas do feminino. Os filhos únicos relatam maior desorganização, e as únicas, mais timidez, irritação e teimosia. Para os filhos do meio, a palavra folgado foi mais presente; 
as filhas do meio citaram ser egoístas e impulsivas.

O terceiro fator diferenciou o grupo dos primogênitos dos filhos do meio. Os primogênitos consideraram características negativas serem mal-humorados e ciumentos, em comparação com os do meio, que se julgaram bastantes críticos. Ser crítico, para eles, foi o fator de maior peso, mantendo considerável distância de média com relação aos outros elementos. Ser sensível foi a característica que, embora tenha obtido apenas metade da média do crítico, também ficou acima das demais de maneira relevante. Esse fator revelou mais consistência com a literatura revisada. Os primogênitos julgaramse mais mal-humorados e ciumentos, o que vai ao encontro ao que afirma Sulloway (1996), de que os primogênitos são mais ciumentos de sua posição, tendo mais tendência a exibir raiva e ter emoções intensas. Fazendo o contraponto, os filhos do meio julgam-se críticos em alta escala e também sensíveis, o que é apoiado por Isaacson e Radish (2002), que dizem que os mais novos são mais vulneráveis, sensíveis à raiva e à culpa, e que também são detalhistas e perfeccionistas, o que poderia contribuir para serem mais críticos do que os mais velhos.

Para o quarto e último fator, os filhos únicos se opuseram aos caçulas. Com quase igual freqüência, os filhos únicos consideraramse desobedientes e estressados, e, em menor escala, chatos. Para os caçulas, a distribuição de elementos não variou muito: a característica diferencial para eles foi julgarem-se pessimistas, e também respondões e vingativos. O fato de os primeiros considerarem-se desobedientes e estressados pode apoiar a idéia de Isaacson e Radish (2002), de que os únicos fazem birra para conseguir o que querem, mas contraria os resultados encontrados por Herrera et al. (2003), em cuja pesquisa a desobediência correspondeu mais aos caçulas do que aos únicos. A característica ser chato, porém, apontada pelos filhos únicos, concorda com a idéia de que os filhos únicos são desagradáveis, segundo a pesquisa de Herrera et al.(2003). Os caçulas, que se consideram pessimistas, respondões e vingativos, de certa forma correspondem ao modelo de Isaacson e Radish (2002), em que os autores dizem que os nascidos em quarto (e último) lugar acham que os outros não os ouvem, sentemse imaturos e também têm o humor insultivo, o que poderia ser ilustrado pela característica respondão.

\section{Conclusão}

A análise da autodescrição de adolescentes considerando gênero e ordem de nascimento indicou de maneira mais visível a diferença entre meninos e meninas. As comparações entre as ordens de nascimento contribuíram menos na formação dos fatores e por vezes também soaram um tanto contraditórias; no entanto, elas sinalizam haver diferenças, mesmo que sutis, entre as formas mais freqüentes de eles se autodefinirem. Isso foi indicado pela freqüência maior ou menor das palavras que surgiram para cada fator em comparação com outro.

O gênero, sendo o principal fator de distribuição das palavras, indica que os estereótipos relacionados aos papéis sociais são mais claros na nossa sociedade do que aqueles relacionados à ordem de nascimento. Isso pode ser apoiado pela hipótese de Hyde (2005), que afirma que as diferenças de gênero se devem aos papéis sociais aprendidos. De fato, os tipos de palavras escolhidas pelos adolescentes para se autodescreverem foram diferentes, no sentido que as meninas sugerem ser mais sensíveis à opinião e aos sentimentos alheios e os meninos mais preocupados consigo mesmos.

No que se refere à ordem de nascimento, os fatores que surgiram para ambas as características (positivas e negativas) foram praticamente os mesmos, com exceção de um, que opôs primogênitos e caçulas, para as positivas, e primogênitos e do meio, para as 
negativas. Esses dados sugerem que a ordem de nascimento também pode ser responsável por suscitar características de personalidade diferentes entre as pessoas, e que há indícios de similaridades entre as (poucas) pesquisas desenvolvidas a esse respeito.

Vale ressaltar aos psicólogos clínicos que padrões comportamentais de clientes podem ser observados em pessoas que ocupam a mesma posição da fratria, quando a família é contextualizada adequadamente e o profissional está atento a percebê-lo. Esse aspecto pode contribuir positivamente nas intervenções psicológicas, pois passa-se a entender a configuração do sistema familiar e a posição do indivíduo em relação a ele, especialmente no que se refere aos irmãos. O estudo da personalidade de forma aprofundada deve levar em conta tais aspectos em futuras pesquisas, de forma a enriquecer o construto teórico da Psicologia do desenvolvimento.

Izabela Tissot Antunes Sampaio

Mestre em Psicologia pela Universidade Federal de Santa Catarina.

E-mail: izabelatissot@gmail.com

\section{Mauro Luís Vieira}

Pós-doutor pela Dalhousie University (Canadá); professor associado do Departamento de Psicologia da Universidade Federal de Santa Catarina.

E-mail: maurolvieira@gmail.com

\section{Endereço para envio de correspondência:}

Universidade Federal de Santa Catarina - Centro de Filosofia e Ciências Humanas, Departamento de Psicologia. Campus Universitário - Núcleo de Estudos e Pesquisas em Desenvolvimento Infantil - Trindade - Florianópolis SC - Brasil, CEP: 88049-900

Recebido 24/07/2008 Reformulado 02/03/2009 Aprovado 12/03/2009

Ernst, C., \& Angst, J. (1983). Birth order: Its influence on personality. New York: Springer-Verlag.

Eysenk, H. J. (1968). Fato e ficção em psicologia. São Paulo: Ibrasa.

Feingold, A. (1994). Gender differences in personality: A metaanalysis. Psychological Bulletin, 116, 429-456.

Fernandes, O. M., Alarcão, M., \& Raposo, J. V. (2007). Posição na fratria e personalidade. Estudos de Psicologia, 24(3), 297-304.

Herrera, N. C., Zajonc, R. B., Wieczorkowska, G., \& Cichomski, B. (2003). Beliefs about birth rank and their reflection in reality. Journal of Personality and Social Psychology, 85(1), 142-150.

Hyde, J. S. (2005). The gender similarities hypothesis. American Psychologist, 60(6), 581-592.

Giavoni, A., \& Tamayo, A. (2000). Inventário dos esquemas de gênero do autoconceito (IEGA). Psicologia: Teoria e Pesquisa, 16(2), 175-184.

Guedes, M. E. F. (1995). Gênero, o que é isso? Psicologia: Ciência e Profissão, 15(1), 4-11.

Ickes, W., \& Turner, M. (1983). On the social advantages of having an older, opposite-sex sibling: Birth order influences in mix-sex dyads. Journal of Personality and Social Psychology, 45(1), 210-222.
Isaacson, C., \& Radish, K. (2002). The birth order effect: How to better understand yourself and others. Avon, $\mathrm{OH}$ : Adams Media.

Manstead, A. S. R., \& Hewstone, M. (Eds.). (1999). The Blackwell encyclopedia of social psychology. Malden, MA: Blackwell.

Matos, M. (2008). Teorias de gênero ou teorias e gênero? Se e como os estudos de gênero e feministas se transformaram em um campo novo para as ciências. Revista de Estudos Feministas, 16(2), 333-357.

Oliveira, A., \& Amâncio, L. (2005). A análise fatorial de correspondências no estudo das representações sociais - as representações sociais do suicídio na adolescência. In A. S. Moreira, B. V. Camargo, J. C. Jesuíno, \& S. M. Nóbrega (Orgs.), Perspectivas teórico-metodológicas em representações sociais (pp. 323-362). João Pessoa: UFPB.

Ribeiro, M. A. (1988). O autoconceito de adolescentes segundo o sexo e a estrutura familiar. Psicologia: Teoria e Pesquisa, 4(2), 85-95.

Sulloway, F. J. (1996). Born to rebel: Birth order, family dynamics, and creative lives. New York: Pantheon Books. 